\title{
Harran Ovası koşullarında şeker otu (Stevia rebaduiana Bertoni)'nun verim ve bazı tarımsal özelliklerinin belirlenmesi
}

\section{Determination of yield and some agricultural characters on stevia (Stevia rebaudiana Bertoni) under the Harran Plain condition}

\author{
Münevver ÇIKMAN ${ }^{1}$ iD, İslim KOŞAR ${ }^{2}$ iD Abdulhabip ÖZEL $^{3^{*}}$ iD \\ ${ }^{1}$ Harran Üniversitesi Fen Bilimleri Enstitüsü, Tarla Bitkileri Anabilim Dalı, 63040, ŞANLIURFA \\ ${ }^{2}$ GAP Tarımsal Araştırma Enstitüsü Müdürlüğü, ŞANLIURFA \\ ${ }^{3}$ Harran Üniversitesi Ziraat Fakültesi, Tarla Bitkileri Bölümü, ŞANLIURFA
}

To cite this article:

Çıkman, M., Koşar, i. \& Özel, A. (2019). Harran Ovası koşullarında şeker otu (Stevia rebaduiana Bertoni)'nun verim ve bazı tarımsal özelliklerinin belirlenmesi. Harran Tarım ve Gıda Bilimleri Dergisi, 23(4): 410-421.

DOI: 10.29050/harranziraat.594997

Address for Correspondence: Abdulhabip ÖZEL

e-mail:

hozel@harran.edu.tr

Received Date:

22.07.2019

Accepted Date:

01.11 .2019

(c) Copyright 2018 by Harran University Faculty of Agriculture. Available on-line www.dergipark.gov.tr/harranziraat
Öz

Bu çalışma, Harran Ovası koşullarında Şeker otu (Stevia rebaduiana Bert.)'nun verim ve bazı tarımsal özelliklerinin belirlenmesi amacıyla; 2016 yılı yaz yetiştirme döneminde GAP Tarımsal Araştırma Enstitüsü Müdürlüğü Koruklu Talat Demirören Araştırma İstasyonunda, kurulan denemenin 2. yılında yürütülmüştür. Denemenin sonuçlarına göre 1. Biçimde, çiçeklenme gün sayısı 127.32 gün, bitki boyu $68.90 \mathrm{~cm}$, ocakta sürgün sayısı 6.82 adet ocak $^{-1}$, yandal sayısı 5.72 adet bitki ${ }^{-1}$, yeşil herba ağırlığı $256.92 \mathrm{~g} \mathrm{bitki}^{-1}$, yeşil yaprak ağırığı $161.52 \mathrm{~g} \mathrm{bitki}^{-1}$, kuru yaprak ağırlığı $53.13 \mathrm{~g} \mathrm{bitki}^{-1}$, kuru yaprak oranı \% 66.47, suda çözünmüş kuru madde oranı yaprakta $\% 2.93$, sapta \%2.26 olarak, 2. biçimde ise; çiçeklenme gün sayısı 30.83 gün, bitki boyu 31.14


$29.82 \mathrm{~g} \mathrm{bitki}^{-1}$, yeşil yaprak ağırlığı $21.70 \mathrm{~g} \mathrm{bitki}^{-1}$, kuru yaprak ağırlığı $6.71 \mathrm{~g} \mathrm{bitki}^{-1}$, kuru yaprak oranı $\% 76.25$, suda çözünmüş kuru madde oranı yaprakta \% 1.86 , sapta \% 1.57 olarak saptanmıştır. Korelasyon analizine göre ise, kuru herba verimi üzerine; bitki boyu, yeşil herba verimi, kuru yaprak verimi, kuru yaprak oranı ve suda çözünmüş kuru madda oranı özelliklerinin önemli ve olumlu etkileri olduğu saptanmıştır. Çalışmadan elde edilen sonuçlar genel olarak değerlendirildiğinde; şeker otu bitkisinden Harran Ovası koşullarında, yılda 2 biçim alınabileceği ancak, birinci bicimde solgunluk hastalığının görülebileceği ve ikinci biçimde bitkilerin sıcaktan olumsuz yönde etkilenebileceği söylenebilir.

Anahtar Kelimeler: Stevia rebaduiana Bertoni, Şeker otu, Bitkisel özellikler, Verim

\section{ABSTRACT}

This study was carried out in the $2^{\text {nd }}$ year of the experiment, which was established in 2016 summer gowing period, at the GAP Agricultural Research Institute, Talat Demirören Research Station, to determine the yield and some agricultural characters on Stevia rebaduiana Bert. under the Harran Plain conditions. According to results of the trial the $1^{\text {st }}$ harvest, average flowering days number was 127.32 day, plant height $68.90 \mathrm{~cm}$, branches number 5.72 pieces plant $^{-1}$, green herb weight $256.92 \mathrm{~g} \mathrm{plant}^{-1}$, green leaf weight $161.52 \mathrm{~g} \mathrm{plant}^{-1}$, dry leaf weight $53.13 \mathrm{~g} \mathrm{plant}^{-1}$, dry leaf ratio $66.47 \%$, water dissolved dry matter ratio in leaf $2.93 \%$ and in stem $2.26 \%$. In the second harvest, flowering days number was 30.83 day, plant height 31.14 $\mathrm{cm}$, number of main branches 5.59 pieces plant ${ }^{-1}$, green herb weight $29.82 \mathrm{~g} \mathrm{plant}^{-1}$, green leaf weight 21.70 g plant $^{-1}$, dry leaf weight 6.71 g plant $^{-1}$, dry leaf ratio $76.25 \%$, water dissolved dry matter ratio in leaf $1.86 \%$ and in stem $1.57 \%$. As a result of the correlation, it was positive and significant relationship between the dry herb weight and plant height, number of leaves per plant, stems number, green herb weight, dry leaf ratio and dissolved matter in water ratio. When the results were evaluated in general; It could be said that two harvests can be taken annually the Stevia plant, but wilt disease can be seen before in the first harvest and the plants can be adversely affected by the high tepmparature in the second harvest period in the Harran Plain conditions.

Key Words: Stevia rebaduiana Bertoni, Plant characterizes, Yield 


\section{Giriş}

Tıbbi ve aromatik bitkiler tarih boyunca gerek tıbbi amaçlı gerekse gıda amaçlı olarak kullanılmış olup günümüzde önemi giderek artmaktadır. Bu bitkiler, tedavi amaçlı kullanımının yanında, kozmetik ürünler, uçucu bitkisel yağlar, sağlık ürünleri, renklendirici boyalar, bitki koruma ürünleri ve bu ürünlerden elde edilen ara ürünler gibi birçok ürünün üretiminde kullanılmaktadır (Lubbe ve Verpoorte, 2011).

Ülkemiz florasında, doğal olarak yetişen, yaklaşık 500 kadar bitki türü geleneksel tıp uygulamalarında kullanılmaktadır. Ancak, ticareti yapılanlarının sayısı 350 kadar olup, bunlardan 140'ının dış satımı yapılmaktadır (Baydar, 2013). Türkiye'de tıbbi ve aromatik bitkiler yoğun olarak Ege, Marmara, Akdeniz, Doğu Karadeniz ve Güneydoğu Anadolu Bölgeleri'nde yetişmekte olup, çoğunlukla doğadan toplanmak sureti ile elde edilip, pazarlanmaktadır. Tüketici ve sanayici taleplerine cevap veren nitelikte, ülkemiz ekolojik koşullarına uygun kaliteli çeşitlerin belirlenmesi, Islah edilmesi, doğaya zarar vermeden toplanması, işleme teknolojilerinin geliştirilmesi, tıbbi ve aromatik bitkilerde, üretim ve pazar olanaklarını geliştirilmesine katkı sağlayacaktır (Bayram ve ark., 2010). Ülkemizin ihtiyaç duyduğu bitkisel etken maddeler ve katkı maddeleri ithalatla karşılanmaktadır (Baydar, 2013). Hiç süphesiz bunlardan birini de doğal tatlandırıcılar oluşturmaktadır. Şeker otu (Stevia rebaduiana Bertoni), 2004 yılından itibaren, Tarım ve Köyişleri Bakanlığının pozitif bitkiler listesinde yer almaktadır (Anonim, 2010). Günümüzde hızla artmaya başlayan obezite, şeker hastalığı (diyabet) ve bunlara bağı ı olarak ortaya çıkan, kalp rahatsızlığı, insanları doğal tatlandırıcılara yönlendirmiştir. Bunlardan biri şeker otu (Stevia rabeduiana Bert.) bitkisidir. Şeker otunun sakkaroza göre 250-300 kat daha fazla tatlıdır. Ayrıca, diğer tatlandırıcılara göre ISI ve $\mathrm{pH}$ stabilitesinin yüksek olması, pişirme ve fırın stabilitesinin olması, alkol içerisinde çözünmesi, ağızda metalimsi tat bırıkmaması ve doğal oluşu şeker otunun tercih edilmesini artırmaktadır.
Bunlardan dolayı dünya pazarlarında şeker otu talebi günden güne artmaktadır (Serfaty ve ark., 2013)

Stevia rebaudiana Bertoni'nin anavatanı Güney Amerika'dır ve Paraguay ve Brezilya'da yetişen bitki, Paraguay Kızılderilileri tarafından "Tatlı Ot" ve "Ballı Yaprak" gibi değişik isimlerle adlandırılmıştır (Carakostas ve ark., 2008). Şeker otu Japonya, Çin, Tayvan, Kore, Meksika, ABD, Tayland, Malezya, Endonezya, Avustralya, Tanzanya, Kanada, Brezilya ve Rusya'da kullanılmakta ve kültürü yapılmaktadır (Ramesh ve ark., 2006; Megeji ve ark., 2005). Şeker otu yaprakları sakkarozdan daha tatlı olan, stevioside, rebaudioside $A, B, C, D, E$ ve dulcosid $A$ glikozitleri içermektedir (Uçar ve ark., 2015; Yadav ve ark., 2011). Bu glikozitlerden stevioside ve rebaudioside $A$ özellikle tatlandırıcı olarak önem arz etmektedir ve bunların miktarlarının fazla olması istenmektedir.

Yapılan çalışmalarda, şeker otu verim ve kalitesi üzerine, ekolojik koşulların, yetiştirme tekniklerinin ve genotiplerin etkili olduğu belirtilmektedir (Shyu ve ark., 1994; Bondarev ve ark., 2003; Maheshwar, 2005; Megeji ve ark., 2005; Sing ve Rao, 2005; Andolfi ve ark., 2006; Aladakatti ve ark., 2011; Kumar ve ark., 2012; Rashid ve ark., 2013; Angeliana ve Tavarini, 2014; Uçar, 2015; Maniruzzaman ve ark., 2016; Tansı ve ark., 2017; Francisco ve ark., 2018).

Şeker otu Ülkemizde de hızlı bir gelişme göstermiş, ilk denemeleri Antalya, Çukurova ve Rize'de (Çaykur öncülüğünde) yapılmıştır (İnanç ve Çınar, 2009). Ülkemiz ihtiyacı ithalatla karşılanan stevia bitkisinin, uygun bölgelerde tarımının yapılması, üreticiler için yeni ve alternatif bir bitki olması, ihtiyacın iç üretimle sağlanması ve ihracat potansiyelinin yüksek olması nedenleriyle önemli bitkidir. Bölgemiz koşullarında ilk defa dedemeye alınan, şeker otu bitkisinin verim potansiyeli ve bitkisel özelliklerini belirlemek, daha sonra yapılacak çalışmalara zemin oluşturması bakımından önem arz etmektedir.

Bu çalışma, Stevia rebaudiana'nın Harran Ovası koşullarında verim ve bazı tarımsal özelliklerini saptamak amacıyla yürütülmüştür. 


\section{Materyal ve Yöntem}

\section{Materyal}

Çalışma, Burhaniye'den temin edilen, tohumlardan üretilen fidelerle, 2015 yılında kurulmuş plantasyonda, 2016 yılı yaz döneminde, GAP Tarımsal Araştırma Enstitüsü Müdürlüğü, Koruklu Talat Demirören Araştırma İstasyonunda, seker otu parsellerinden, tesadüfen seçilmiş 87 bitkide yürütülmüştür.

Araştırma alanı toprağı, bölgede geniş yayılım gösteren Harran Toprak Serisinden oluşmuştur. Harran serisi toprakları, derin profilli topraklar olup, alüviyal ana materyalli, düz ve düze yakın eğimli, tipik kırmızı profilli, killi tekstürlü ve tüm profil kireçli topraklardır. Bu toprakların katyon değişim kapasitesi (KDK) yüksektir (Dinç ve ark., 1988). Deneme alanın toprak analizi sonuçlarına göre, $\mathrm{pH}$ değerinin 8.02, kireç oranının \%27.7, organik madde miktarının \%1.43, elverişli $\mathrm{P}_{2} \mathrm{O}_{5}{ }^{\prime}$ in $3.13 \mathrm{~kg} \mathrm{da}^{-1}$ ve elverişli $\mathrm{K}_{2} \mathrm{O}^{\prime}$ in $116.4 \mathrm{~kg} \mathrm{da}^{-1}$ olduğu belirlenmiştir. Bu veriler doğrultusunda, deneme alanı toprak yapısının hafif alkali karakterde olduğu, organik madde ve elverişli fosfor bakımından fakir, kireç ve potasyum bakımından zengin olduğu söylenebilir.

Şanlıurfa, karasal iklim bölgesine girmekle beraber, Akdeniz ikliminin etkisi de görülmektedir. Yazları kurak ve sıcak, kışları ılık geçmektedir. Yaz mevsiminde gündüz sıcaklığı 44 ${ }^{\circ} C^{\prime}$ nin üzerine çıkmaktadır. Bağıl nemin çok düşük oluşu, buharlaşmayı arttırmaktadır (Atalay ve Mortan, 2006).

Deneme alanının, 2016 yılı ve uzun yıllar ortalamasına ilişkin iklim değerleri Çizelge 1.'de verilmiştir.

Çizelge 1. Deneme yılı ve uzun yıllar ortalamasına ilişkin bazı iklim verileri

Table 1. Some climatic data for the trial year and the average for many years

\begin{tabular}{|c|c|c|c|c|c|c|c|}
\hline \multirow{2}{*}{$\begin{array}{c}\text { Aylar } \\
\text { Months }\end{array}$} & \multirow{2}{*}{$\begin{array}{l}\text { Yillar } \\
\text { Years }\end{array}$} & \multicolumn{3}{|c|}{ Sıcaklık/Temperature $\left({ }^{\circ} \mathrm{C}\right)$} & \multirow{2}{*}{$\begin{array}{c}\text { Yağış } \\
\text { Precipitation }\left(\mathrm{kg} / \mathrm{m}^{2}\right)\end{array}$} & \multirow{2}{*}{$\begin{array}{c}\text { Nisbi Nem } \\
\text { Humidity (\%) }\end{array}$} & \multirow{2}{*}{$\begin{array}{c}\text { Güneşlenme } \\
\text { Insolation (sa/da) }\end{array}$} \\
\hline & & Min. & Max. & Ort. & & & \\
\hline Ocak & 2016 & 1.9 & 9.8 & 5.3 & 87.3 & 70.2 & 4.1 \\
\hline January & U.Y. & 2.2 & 10.0 & 5.6 & 84.8 & 70.4 & 4.3 \\
\hline Şubat & 2016 & 2.8 & 11.8 & 11.3 & 69.0 & 67.3 & 5.1 \\
\hline February & U.Y. & 2.9 & 12.0 & 6.9 & 75.5 & 67.1 & 5.1 \\
\hline Mart & 2016 & 5.7 & 16.3 & 13.2 & 62.7 & 59.9 & 6.3 \\
\hline March & U.Y. & 6.0 & 16.9 & 10.9 & 65.4 & 60.7 & 6.8 \\
\hline Nisan & 2016 & 10.2 & 22.2 & 15.5 & 49.6 & 56.6 & 7.8 \\
\hline April & U.Y. & 10.5 & 22.3 & 16.2 & 49.7 & 56.7 & 7.8 \\
\hline Mayıs & 2016 & 15.1 & 28.6 & 22.6 & 25.6 & 44.9 & 9.9 \\
\hline May & U.Y. & 15.5 & 28.5 & 22.1 & 29.4 & 45.4 & 10.2 \\
\hline Haziran & 2016 & 20.4 & 34.5 & 29.1 & 3.4 & 32.7 & 12.1 \\
\hline June & U.Y. & 20.7 & 35.0 & 28.3 & 4.0 & 33.2 & 12.3 \\
\hline Temmuz & 2016 & 24.2 & 38.4 & 34.9 & 0.6 & 30.1 & 12.3 \\
\hline July & U.Y. & 24.3 & 38.7 & 31.9 & 0.6 & 30.5 & 12.5 \\
\hline Ağustos & 2016 & 23.8 & 38.1 & 32.3 & 0.6 & 32.7 & 11.4 \\
\hline August & U.Y. & 24.0 & 38.7 & 31.5 & 0.8 & 33.3 & 11.6 \\
\hline Eylül & 2016 & 19.8 & 33.8 & 27.9. & 2.5 & 35.5 & 9.9 \\
\hline September & U.Y. & 20.0 & 33.6 & 26.4 & 2.9 & 36.0 & 9.8 \\
\hline Ekim & 2016 & 14.4 & 26.9 & 20.8 & 24.4 & 45.9 & 7.8 \\
\hline October & U.Y. & 14.6 & 26.8 & 20.1 & 25.7 & 46.5 & 7.5 \\
\hline Kasım & 2016 & 8.3 & 18.7 & 14.0 & 44.2 & 60.6 & 5.8 \\
\hline November & U.Y. & 8.4 & 18.5 & 12.6 & 46.0 & 60.2 & 5.8 \\
\hline Aralık & 2016 & 3.9 & 11.9 & 7.0 & 78.0 & 71.2 & 4.0 \\
\hline December & U.Y. & 4.1 & 11.9 & 7.3 & 79.5 & 70.4 & 3.8 \\
\hline Toplam & 2016 & & & & 447.9 & & \\
\hline Total & U.Y. & & & & 464.3 & & \\
\hline
\end{tabular}

U.Y., Uzun Yillar Ortalaması/Average for many years

Çizelge 1'de, 2016 yılı vejetasyon döneminde saptanan iklim değerlerinin uzun yıllar ortalamalarına genel olarak benzerlik gösterdiğinin ve toplam yağış miktarının deneme 
yılında $447.9 \mathrm{~kg}$, uzun yıllar ortalamasının ise $464.3 \mathrm{~kg}$ olduğu ve toplam yağış miktarının deneme yılında daha az olduğu, deneme yılı sıcaklık değerinin uzun yıllar ortalamalarına genel olarak, benzer olduğu ancak, 2016 yılında Şubat, Mart ve Temmuz aylarının ortalama sıcaklığının, uzun yıllar ortalamasının biraz üzerinde gerçekleştiği, deneme yılında Haziran, Temmuz, Ağustos ve Eylül aylarında hiç yağışın düşmediği ve genel olarak, 2016 yılında uzun yıllar ortalama değerlerinden daha düşük miktarda yağışın düştüğü, deneme yılının ortalama nem oranının genel olarak, uzun yıllar nem ortalamasından fazla olduğu, Nisan, Mayıs ve Kasım aylarında ise benzer olduğu, 2016 yılında Nisan, Mayıs ve Haziran aylarının, uzun yıllar güneşlenme süresi ortalamasının altında gerçekleştiği görülmektedir.

\section{Yöntem}

Araştırma, 2016 yazlık ürün yetiştirme döneminde, Mart 2015 de dikilmiş olan şeker otu bitkilerinin 2. Yılında, belirlenen bitkilerin verim ve tarımsal kararkterlerini belirlemek amacıyla, yürütülmüştür. Denemede bitkiler, sıra arası 40 $\mathrm{cm}$ ve sıra üzeri $30 \mathrm{~cm}$ olacak şekilde dikilmiştir. Deneme alanına dikimden önce toplam $10 \mathrm{~kg} \mathrm{da}^{-1}$ azot ve fosfor gelecek şekilde, 20-20-0 taban gübresi verilmiştir. Deneme yılında ise; ilk gübre 31 Mart'ta sürgünlerin çıkış gösterdiği dönemde, dekara $5 \mathrm{~kg} \mathrm{da}^{-1}$ ve 1 biçimden sonra $5 \mathrm{~kg} \mathrm{da}^{-1}$ olacak şekilde \% 46 üre gübresi, 2 defada uygulanmıştır. Mart sonundan itibaren, yaz boyunca haftada bir sulama yapılmıştır.

Denemede, bitkilerin gelişmelerine bağlı olarak, toplam 3 defa, elle yabancı ot mücadelesi yapılmıştır. Denemede, sadece 1 bitki küsküt sarımı nedeniyle kesilip yakılmıştır. TemmuzAğustos aylarında artan sıcaklık nedeniyle, 4 bitkide sararma ve güneş yanıklığı görülmüştür. Ağustos ayının ilk haftasında, artan sulama ile bitkilerde Fusarium hastalığı görülmüş ve aynı hafta, Hymexazol etken maddeli ilaçtan dekara $500 \mathrm{ml}$ gelecek şekilde, ilaçlama yapılmıştır. Biçimler, bitkilerin çiçeklenme başlangıcında, bitkiler ayrı ayrı elle biçilmiştir. İlk biçimden sonra bitkilerin gelişme durumlarına göre tekrar çiçeklenen bitkilerden 2. biçimler alınmıştır.

\section{Araştırmada incelenen özellikler}

Denemede çiçeklenme başlangıcında bitkiler (87 bitki) ayrı ayrı hasat edilerek, çiçeklenme gün sayısı (gün), bitki boyu $(\mathrm{cm})$, sürgün sayısı (adet ocak $^{-1}$ ), yan dal sayısı (adet sap ${ }^{-1}$ ), yeşil herba verimi (g bitki ${ }^{-1}$ ), yeşil yaprak verimi $\left(\mathrm{g} \mathrm{bitki}^{-1}\right)$, drog herba verimi ( $\mathrm{g}$ bitki ${ }^{-1}$ ), drog yaprak verimi ( $\mathrm{g}$ $\mathrm{da}^{-1}$ ) ve yaprak oranı (\%) gözlemleri, Uçar (2015)'a göre alınmıştır.

\section{Suda çözünmüş kuru madde oranı (\%)}

Her bitkiden alınan kurutulmuş sap ve yaprak örnekleri ögütülmüş ve 5'er gram alınarak, plastik tüplere konulmuş ve üzerlerine $10 \mathrm{ml}$ saf su konularak, dakikada $4100 \mathrm{rpm}$ hızda, santrifuj ile 30 dakika çalkalanmış ve çıkan örnekler 24 saat oda koşullarında bekletilmiştir. Çöken kuru maddenin üzerindeki sulu çözelti, pipet yardımıyla alınarak, her örnekte dijital refraktometre ile suda çözünen kuru madde oranları belirlenmiştir.

\section{Verilerin değerlendirilmesi}

Araştırmadan elde edilen veriler, Excel paket programı kullanılarak aritmetik ortalamaları, standart sapmaları ve korelasyon katsayıları hesaplanmıştır.

\section{Araştırma Bulguları ve Tartışma}

\section{Çiçeklenme gün sayısı}

Deneme süresince şeker otunda, saptanan çıkış ve biçim tarihleri Çizelge 2.'de verilmiştir.

Çizelge 2. Harran ovası koşullarında şeker otunda, bitkilere göre saptanan biçim tarihleri Table 2. Harvesting dates of sweet leaf according to plants under the Harran plain conditions

\begin{tabular}{rcc} 
Hasat sırası & Örnek sayısı & Hasat tarihleri \\
Harvesting & Number of samples & Harvest dates \\
\hline 1. Biçim/Harvest & 87 & 24 Haziran-17 Ağustos \\
2. Biçim/Harvest & 67 & 19 Temmuz-1 Eylül \\
\hline
\end{tabular}


Denemede, birinci biçimde 87 bitki, 24 Haziran'dan itibaren 17 Ağustos'a kadar farklı zamanlarda çiçeklenmişlerdir. Hasat edilen bu bitkilerden, 67 adedi tekrar çiçeklenmiş ve 19 Temmuz'dan itibaren 1 Eylül'e kadar, 2. Biçimler çiçeklenme tarihlerine göre yapılmıştır (Çizelge 2.).
Şeker otu bitkilerinde saptanan çiçeklenme gün sayısı (gün), bitki boyu (cm), sürgün sayısı (adet ocak $^{-1}$ ) ve yandal sayısı (adet sap $\left.^{-1}\right)^{\prime}$ na ilişkin ortalamalar ve standart sapma değerleri Çizelge 3.'te verilmiştir.

Çizelge 3. Harran ovası koşullarında şeker otunda saptanan çiçeklenme gün sayısı, bitki boyu, sürgün sayısı ve yandal sayısına ilişkin ortalamalar ve standart sapma değerleri

Table 3. Mean and standard deviation values number of flowering days, plant height, sprout number and branches number detected in sweet leaf under the Harran plain conditions

\begin{tabular}{|c|c|c|c|c|c|}
\hline $\begin{array}{l}\text { Hasat Sırası } \\
\text { Harvesting }\end{array}$ & $\begin{array}{c}\text { Örnek sayısı } \\
\text { Samples Number }\end{array}$ & $\begin{array}{l}\text { Minimum } \\
\text { Minimum }\end{array}$ & $\begin{array}{l}\text { Maksimum } \\
\text { Maximum }\end{array}$ & $\begin{array}{l}\text { Ortalama } \\
\text { Average }\end{array}$ & $\begin{array}{c}\text { Standart sapma } \\
\text { Standard deviation }\end{array}$ \\
\hline \multicolumn{6}{|c|}{ Çiçeklenme Gün Sayısı (gün)/Flowering Day Number } \\
\hline 1. Biçim/Harvest & 87 & 92.00 & 139.00 & 127.32 & \pm 9.99 \\
\hline 2. Biçim/Harvest & 67 & 23.00 & 41.00 & 30.83 & \pm 8.16 \\
\hline Ortalama/Average & & 57.50 & 90.00 & & \\
\hline \multicolumn{6}{|c|}{ Bitki Boyu/Plant Height (cm) } \\
\hline 1. Biçim/Harvest & 87 & 35.00 & 95.00 & 68.90 & \pm 13.20 \\
\hline 2. Biçim/Harvest & 67 & 20.00 & 55.00 & 31.14 & \pm 7.61 \\
\hline Ortalama/Average & & 27.5 & 75.00 & & \\
\hline \multicolumn{6}{|c|}{ Sürgün Sayısı (adet ocak ${ }^{-1}$ )/Sprout Number (pieces plant ${ }^{-1}$ ) } \\
\hline 1. Biçim/Harvest & 87 & 1.00 & 25.00 & 6.82 & \pm 4.87 \\
\hline 2. Biçim/Harvest & 67 & 1.00 & 11.00 & 5.59 & \pm 2.52 \\
\hline Ortalama/Average & & 1.00 & 18.00 & & \\
\hline \multicolumn{6}{|c|}{ Yandal Sayısı (adet sap ${ }^{-1}$ )/Branches Number (pieces pant ${ }^{-1}$ ) } \\
\hline 1. Biçim/Harvest & 87 & 0 & 16.00 & 5.72 & \pm 6.34 \\
\hline 2. Biçim/Harvest & 67 & 0 & 5.00 & 2.67 & \pm 1.18 \\
\hline Ortalama/Average & & 0 & 10.50 & & \\
\hline
\end{tabular}

Çizelge 3.'te, çiçeklenme gün değerlerinin 1. Biçimde, 92.00-139.00 gün arası değiştiği ve ortalama $127.32 \pm 9.99$ gün, 2. Biçimde ise, 23.0041.00 gün arasında değişm gösterdiği ve ortalama $30.83 \pm 8.16$ gün olduğu görülmektedir. Çiçeklenme gün sayısı 2. Biçimde, 1. Biçimden daha kısa sürede gerçekleşmiştir. Ayrıca, standart sapma değerlerinin her iki biçimde de yüksek olduğu belirlenmiştir. Standart sapma değerlerinin yüksek olması, bitkilerin genotipik olarak standart olmadığının bir göstergesi olarak kabul edilebilir. Artan sıcaklık ve güneşlenme süresinin (Çizelge 1.) bazı bitkilerin, 1. Biçimden sonra tekrar çiçeklenmemesinin nedeni olduğu söylenebilir.

Bitkilerde çiçeklenme üzerine, gün uzunluğu etkili bir faktördür. Birçok bitkide çiçeklenmenin olabilmesi için, uzun veya kısa süre, belirli bir gün uzunluğu etkisinde kalması gerekmektedir (Ceylan
1994). Zaidan (1980) fotoperiyotun şeker otu bitkisinde çiçeklenmeyi etkilediğini ve bitkinin bir kısa gün bitkisi olduğunu belirtmektedirler. Aynı zamanda, şeker otu mutlak kısa gün bitkisi olduğunu ve kısa günlerde çiçeklenmenin başladığı Kang ve Lee (1981) tarafından bildirilmiştir. Bulgularımız araştıcıların bildirdikleriyle kısmen uyumludur. Ancak, şeker otunun Harran Ovası koşullarında 24 Haziran-1 Eylül tarihleri arasında çiçek oluşturması, bu konunuda soru işaretleri barındırmaktadır. Uçar (2015), Antalya koşullarında şeker otu bitkisinin 159-177 gün arasında çiçeklendiğini bildirmiştir. Bulgularımız, bu değerlerin altındadır. Bu farklılık, ekolojik ve genotipik farklılıktan kaynaklanabilir. Nitekim, Maheshwar (2005), vejetatif büyüme sırasındaki düşük sıcaklıklar ve kısa gün koşulları şeker otunda erken çiçeklenmeye neden olduğunu bildirmektedir. 
Bitki boyu

Çizelge 3.'te görüldüğü gibi, 1. Biçimde 87 bitkide ve 2. Biçimde 67 bitkide gözlem alınmıştır. íkinci biçimde gözlem alınmayan 20 şeker otu bitkisinde 1. Biçim sonrası bitkilerin rozet halinde kaldığı ve canlılığını devam ettirdiği gözlemlenmiştir. Bitki boyu değerleri, 1. Biçimde 35.00-95.00 cm arasında değişim göstermiş ve ortalama $68.90 \pm 13.20 \mathrm{~cm}$ olarak, 2. Biçimde ise, 20.00-55.00 cm arasında değişim göstermiş ve ortalama $31.14 \pm 7.61 \mathrm{~cm}$ olarak saptanmıştır. Popülasyonda bitki boyları yönünden bitkiler arasında her iki biçimdede büyük farklılıklar saptanmıştır. Ayrıca, biçimler arasında da, bitki boyu yönünden büyük farklılıklar gözlenmiştir. Buna göre, 2. Biçimde bitki boylarında büyük bir azalma saptanmıştır. Bitkiler arası bitki boyu değişimi genotipik farklılıktan, biçimler arasındaki farklılık ise, ekolojik koşullarından kaynaklanabilir. Denemede, 1. Biçimden sonra, bitkiler daha sıcak ve kuru hava koşullarına (Çizelge 1.) maruz kalmıştır. Bu durum, bitkilerin gelişimini olumsuz yönde etkilemiş ve bitki gelişimini engelleyerek 2 . Biçim alınan bitkilerin boylarının kısa kalmasına neden olmuş olabilir. Bulgularımız, Hindistan koşullarında $43{ }^{\circ} C^{\prime}$ ıın üzerindeki sıcaklıkların şeker otu bitkilerine zarar vereceğini bildiren Singh ve Rao (2005)'nın bulgularıla desteklenmektedir.

Bitki boyu değerlerimiz, 1. Biçimde, Angeliana ve Tavaranini (2014) bildirdiği değerlere benzer iken, 2. Biçimde, bidirilen bitki boylarından düşük bulunmuştur. Bu durum ekolojik koşullardan ve genotipik farklılıklardan kaynaklanabilir. Maheshwar (2005), uygun olmayan iklim koşullarında şeker otunun çiçeklenme eğilimine gireceğini ve bitki boyunun kısalacağını, Lee ve ark. (1980), bitki boyunun 50-70 cm olduğunu ve ekim sıklı̆̆ndan etkilendiğini, Shyu ve ark. (1994) biçim sırası, zamanı ve yağış miktarının şeker otunda bitki boyunu önemli derecede etkilediğini ve Aladakatti (2011) sulama miktarı arttıkça, bitki boyunda artış görüldüğünü ve bitki gelişimini olumsuz etkilediğini bildirmişlerdir.

\section{Sürgün sayısı}

Çizelge 3.'te görüldüğü gibi ocakta sürgün sayısı değerleri, 1. Biçimde 1.00-25.00 adet ocak ${ }^{-1}$, ortalama $6.82 \pm 4.87$ adet ocak $^{-1}, 2$. Biçimde ise 1.00-11.00 adet ocak ${ }^{-1}$, ortalama 5.59 \pm 2.52 adet ocak $^{-1}$ olduğu saptanmıştır. Ocakta sürgün sayıları biçimlere ve bitkilere göre büyük farklılık göstermiştir. Bitkiler arasında, özellikle 1. Biçimde, standart sapma yüksek çıkmış, bu durum genotipik varyasyondan kaynaklanabilir. 2. Biçimde daha düşük ocakta sap sayısı saptanmıştır. Bulgularımızın, 2. Biçimde ocakta sap sayısının daha düşük olduğunu bildiren Uçar'ın (2015) bulgularıyla, uyumlu olduğu görülmektedir. Araştırıcı ayrıca, artan sıcaklık ve yağış miktarının yetersizliği gibi faktörlerin, şeker otunda dallanmayı olumsuz yönde etkilediğini vurgulamaktadır. Singh ve Rao (2005), sıcaklığın yükselmesi ile bitkinin strese girmeye başladığını bundan dolayı bitki gelişiminin engellediğini belirtmişlerdir. Alladakatti (2011), şeker otu bitkisinde sürgün sayısının birim alandaki bitki sayısından ve bitki yaşından etkilendiğini belirlemiştir.

\section{Yandal sayısı}

Çizelge 3.'te, yandal sayısı değerlerinin, 1. Biçimde $\quad 0.00-16.00$ adet $\operatorname{sap}^{-1}$, ortalama $5.72 \pm 6.34$ adet $\operatorname{sap}^{-1}, 2$. Biçimde ise 0.00-5.00 adet sap $^{-1}$, ortalama $2.67 \pm 1.18$ adet sap $^{-1}$ olduğu görülmektedir. Sapta yandal sayısı değerleri, biçimlere ve bitkilere göre büyük farklılık göstermiştir. Bitkiler arasında, özellikle 1. Biçimde, standart sapma yüksek çıkmış, bu durum genotipik varyasyondan kaynaklanabilir. 2. Biçimde daha düşük yandal sayısı saptanmıştır. Yandal sayısı vejetasyon süresine ve yetiştirme tekniğine bağlı olarak değişen bir özelliktir. Çiçeklenme ile biçimi yapılan şeker otu bitkilerinde, yandal sayılarının ilk biçimde yüksek ve ikinci biçimde daha düşük belirlenmesi, iklim faktörlerinin etkisinden kaynaklı olduğu söylenebilir. Tansı ve ark. (2017), bitkini gelişme durumuna göre, yan dal sayısının değiştiğini ve çiçeklenme sırasında, dal sayısının en yüksek 
olduğunu bildirmişlerdir. Maheshwar (2005), şeker otu bitkisinde ekim sıklığı ve gün uzunluğunun ana ve yan dallanmalarda artışa neden olduğunu bildirirken, Aladakatti (2011) ve Uçar (2015) bitki yaşının dallanmaya etkisinin yüksek olduğunu bildirmiştir.

\section{Yeşil herba verimi}

Denemede, 2016 yılı yaz dönemi, şeker otu bitkisinde, farklı hasat zamanlarında saptanan yeşil herba verimi $\left(\mathrm{g}\right.$ bitki $\left.^{-1}\right)$, yeşil yaprak verimi ( $\mathrm{g}$ bitki $^{-1}$ ), kuru herba verimi (g bitki ${ }^{-1}$ ) ve kuru yaprak verimi (g bitki ${ }^{-1}$ ) değerlerine ilişkin ortalama ve standart sapma sonuçları Çizelge 4.'de verilmiştir.

Çizelge 4. Harran ovası koşullarında şeker otunda saptanan yeşil herba verimi, yeşil yaprak verimi, kuru herba verimi ve kuru yaprak verimi değerlerine ilişkin ortalamalar ve standart sapma değerleri

Table 4. Mean and standard deviation values green herb yield, green leaf yield, dry herb yield and dry leaf yield detected in sweet leaf under the Harran plain conditions

\begin{tabular}{|c|c|c|c|c|c|}
\hline $\begin{array}{l}\text { Hasat Sırası } \\
\text { Harvesting }\end{array}$ & $\begin{array}{c}\text { Örnek sayısı } \\
\text { Samples Number }\end{array}$ & $\begin{array}{l}\text { Minimum } \\
\text { Minimum }\end{array}$ & $\begin{array}{l}\text { Maksimum } \\
\text { Maximum }\end{array}$ & $\begin{array}{l}\text { Ortalama } \\
\text { Average }\end{array}$ & $\begin{array}{l}\text { Standart sapma } \\
\text { Standard deviation }\end{array}$ \\
\hline \multicolumn{6}{|c|}{ Yeşil Herba Verimi (g bitki ${ }^{-1}$ )/Green Herb Yield (g plant ${ }^{-1}$ ) } \\
\hline 1. Biçim/Harvest & 87 & 26.00 & 1080.10 & 256.92 & \pm 191.60 \\
\hline 2. Biçim/Harvest & 67 & 8.00 & 140.70 & 29.82 & \pm 26.02 \\
\hline Ortalama/Average & & 17.00 & 610.40 & & \\
\hline \multicolumn{6}{|c|}{ Yeşil Yaprak Verimi (g bitki ${ }^{-1}$ )/Green Leaf Yield (g plant ${ }^{-1}$ ) } \\
\hline 1. Biçim/Harvest & 87 & 10.10 & 499.10 & 161.52 & \pm 120.36 \\
\hline 2. Biçim/Harvest & 67 & 6.50 & 54.40 & 21.70 & \pm 17.61 \\
\hline Ortalama/Average & & 8.30 & 276.75 & & \\
\hline \multicolumn{6}{|c|}{ Kuru Herba Verimi (g bitki ${ }^{-1}$ )/Dry Herb Yield (g plant ${ }^{-1}$ ) } \\
\hline 1. Biçim/Harvest & 87 & 27.70 & 221.10 & 82.13 & \pm 41.24 \\
\hline 2. Biçim/Harvest & 67 & 3.60 & 45.70 & 10.71 & \pm 7.97 \\
\hline Ortalama/Average & & 15.65 & 133.40 & & \\
\hline \multicolumn{6}{|c|}{ Kuru Yaprak Verimi (g bitki ${ }^{-1}$ )/Dry Leaf Yield $\left(\right.$ g plant $^{-1}$ ) } \\
\hline 1. Biçim/Harvest & 87 & 1.90 & 186.10 & 53.13 & \pm 35.54 \\
\hline 2. Biçim/Harvest & 67 & 0.60 & 26.70 & 6.71 & \pm 5.39 \\
\hline Ortalama/Average & & 1.25 & 106.40 & & \\
\hline
\end{tabular}

Çizelge 4.'de görüldüğü gibi, yeşil herba verimi değerleri, 1. Biçimde 26.00-1080.10 $\mathrm{g} \mathrm{bitki}^{-1}$, ortalama $256.92 \pm 191.60 \mathrm{~g} \mathrm{bitki}^{-1}$ 2. Biçimde ise, 8.00-140.70 g bitki ${ }^{-1}$, ortalama $29.82 \pm 26.02 \mathrm{~g}$ bitki ${ }^{-1}$ olarak saptanmıştır. Yeşil herba ağırlığı değerleri, biçimlere ve bitkilere göre büyük farklılık göstermiştir. Bitkiler arasında, standart sapma yüksek çıkmış, bu durum genotipik varyasyondan kaynaklanabilir. 2. Biçimde daha düşük yeşil herba ağırlığı saptanmıştır. Genel olarak, biçim sırasının yeşil herba verimini etkilediği görülmüştür. Bulgularımız, biçim zamanının herba verimini önemli derecede etkilediğini, artan gün sayısına paralel olarak, bitkide yaprak kalınlığını arttırdığını ve bunun da verimi etkilediğini bildiren Shyu (1994)'nu bulgularıyla uyumlu bulunmuştur.

Denemede, 1. Biçimden sonra tüm bitkiler çiçeklenmediği için, çiçeklenen 67 bitkide 2 . biçimler alınmıştır. Bitkiler arasında ortaya çıkan bu farklılık genotipik farklılıktan, biçimler arasındaki farklılık ise ekolojik koşullardaki farklııklardan kaynaklanabileceği, özellikle, Temmuz ve Ağustos aylarında artan sıcaklarla bitki gelişiminin yavaşlaması, 2 . Biçime gelen bitki sayısının düşmesine ve yeterli biyokütleye ulaşmamasına neden olmuştur. Nitekim deneme yılı iklim verileri (Çizelge 1.) incelendiğinde, 1. Biçimden sonra, bitkilerin daha sıcak ve kuru bir iklime maruz kaldığı görülebilir. Bilindiği gibi, herba verimi üzerine, bitki boyu, sap sayısı, yandal sayısı gibi vejetatif aksamların katkısı büyüktür (Çizelge 6). Bu nedenle, yeşil herba verimi, yüksek sıcaklıktan ve düşük nemden olumsuz şekilde etkilenmiştir. Bulgularımız, sıcaklığın yükselmesi ile bitkinin strese girmeye 
başladığı bundan dolayı bitki gelişiminin engellediğini bildiren Singh ve Rao (2005)'nun bulgularıyla uyumlu bulunmuştur.

\section{Yeşil yaprak verimi}

Çizelge 4.'te görüldüğü gibi, yeşil yaprak verimi değerleri 1. Biçimde, 10.10-499.10 $\mathrm{g} \mathrm{bitki}^{-1}$, ortalama $161.52 \pm 120.36 \mathrm{~g} \mathrm{bitki}^{-1}, 2$. Biçimde ise 6.50-54.40 $\mathrm{g} \mathrm{bitki}^{-1}$, ortalama $21.70 \pm 17.61 \mathrm{~g} \mathrm{bitki}^{-1}$ olarak saptanmıştır. Yeşil yaprak verimi değerleri, biçimlere ve bitkilere göre büyük farklılık göstermiştir. Bitkiler arasında, standart sapma yüksek çıkmış, bu durum genotipik varyasyondan kaynaklanabilir. Şeker otu bitkisinde en fazla steviol glikozit içeren organlar yapraklar olduğundan (Bondarev ve ark., 2003), yaprak verimi oldukça önemlidir. Farklı zamanlarda hasat edilen bitkilerin yeşil yaprak verimi üzerine etkisi değerlendirildiğinde, 1. Biçim zamanı ile 2. Biçim zamanı arasında fark bariz şekilde görülmektedir (Çizelge 4.). 1. Biçim, 2. Biçime göre uygun, güneşlenme süresi ve sıcaklık gibi, iklim koşulları nedeniyle bitki boyunda artış ve bununla beraber yeşil yaprak veriminde de artışa neden olmuştur. Allam (2001), şeker otunda, vetatif gelişim üzerine, yüksek sıcaklık, yağış miktarı ve güneşlenme süresinin önemli yeri olduğunu bildirmiştir. Denemede özellikle 2. Biçimdeki düşüş, yüksek sıcaklık ve düşük nibi neme (Çizelge 1.) bağlı olarak ortaya çıkmış olabilir. Nitekim, Singh ve Rao (2005)'nun bildirdiklerine göre de yüksek sıcaklıklar şeker otu bitkisinin gelişimini olumsuz etkilemektedir. Aladakatti (2011), düşük biyokütle üretiminin, düşük verimine neden olduğunu bilirmektedir. Uygun koşullarda yetişen şeker otu 1. Biçimde, biyokütlenin artışıyla, yeşil yaprak veriminde de artışa neden olmuştur.

\section{Kuru herba verimi}

Çizelge 4.'te görüldüğü gibi, kuru herba verimi değerleri 1. Biçimde, 27.70-221.10 g bitki ${ }^{-1}$ arasında değişim göstermiş ve ortalama $82.13 \pm 41.24 \mathrm{~g} \mathrm{bitki}^{-1}$ olarak, 2. Biçimde ise, 3.60$45.70 \mathrm{~g} \mathrm{bitki}^{-1}$ arasında değişim göstermiş ve ortalama $10.71 \pm 7.97 \mathrm{~g} \mathrm{bitki}^{-1}$ olarak saptanmıştır. Kuru herba verimi yönünden, hem biçimler arasında hemde, populasyondaki bitkiler arasında farklılıklar gözlenmiştir. Bitki boyu, sürgün sayısı, yandal sayısı (Çizelge 3.), yeşil herba ve yeşil yaprak verimi sonuçlarının, 1 . Biçimde 2 . Biçimlerden yüksek oluşu, 1. Biçimden elde edilen kuru herba veriminin de yüksek olmasını sağlamıştır. Bitkiler, 1. Biçimden önce, 2. Biçime kadar geçen sürede, daha uygun iklim koşullarna maruz kalması nedeniyle, biçimler arası verim farkı büyük olmuştur. Bulgularımız Singh ve Rao (2005)'nun bildirimleriyle benzerlik göstermektedir. Allam (2001) şeker otunda, vetatif gelişim üzerine, sıcaklık, yağış miktarı ve güneşlenme süresinin önemli yeri olduğunu bildirmiştir. Aladakatti (2011), düşük biyokütle üretiminin, düşük verime neden olduğunu bildirmektedir. Uygun koşullarda yetişen şeker otu, 1. Biçimde, biyokütlenin artışıyla, kuru herba veriminde de artışa neden olmuştur.

\section{Kuru yaprak verimi}

Çizelge 4.'te görüldüğü gibi, bitki başına kuru yaprak verimi 1 . Biçimde, $1.90-186.10 \mathrm{~g} \mathrm{bitki}^{-1}$ arasında değişmiş olup, ortalama $53.13 \pm 35.54 \mathrm{~g}$ bitki $^{-1} 2$. Biçimde ise, $0.60-26.70 \mathrm{~g} \mathrm{bitki}^{-1}$ arasında değişmiş olup, ortalama $6.71 \pm 5.39 \mathrm{~g} \mathrm{bitki}^{-1}$ olarak saptanmıştır. Kuru yaprak verimi yönünden hem biçimler arası hemde, populasyondaki bitkiler arasında farklııklar gözlenmiştir. Bu durum genotipik ve iklim faktörlerinden kaynaklanabilir. Şeker otunda kuru yaprak verimi ile bitki boyu, dal sayısı, bitki başına yaprak sayısı ve kuru madde birikimi arasında pozitif bir ilişki bulunmaktadır. Bu nedenle, özellikler arasında benzerlik görülmektedir.

\section{Yaprak oranı}

Denemede, 2016 yılı yaz dönemi şeker otu bitkisinde, yaprak oranı (\%) ve suda çözünmüş kuru madde oranı (\%) değerlerine ilişkin sonuçları Çizelge 5.'te verilmiştir.

Çizelge 5.'te, şeker otunda yaprak oranının 1. Biçimde, \%49.01-93.00 arasında değiştiği ve ortalama \%66.47 \pm 7.21 olduğu 2. Biçimde ise, $\% 44.00-94.00$ arasında değiştiği ve ortalama $\% 76.25 \pm 8.12$ olduğu görülmektedir. Genel olarak, 2.Biçim yaprak oranının daha yüksek olduğu 
saptanmıştır. Bu durum, 2. Biçimde, daha kısa vejetasyon süresine sahip olan şeker otu bitkilerinin, daha kısa boylu olmalarından (Çizelge
3.) ve daha az sap ağırlığına sahip olmalarından kaynaklanabilir.

Çizelge 5. Harran ovası koşullarında şeker otunda saptanan yaprak oranı, yaprakta ve sapta suda çözünmüş kuru madde oranına ilişkin ortalamalar ve standart sapma değerleri

Table 5. Mean and standard deviation values leaf ratio, water dissolved dry matter ratio in leaf and in stem detected in sweet leaf under the Harran plain conditions

\begin{tabular}{lccccc}
\hline $\begin{array}{c}\text { Hasat Sırası } \\
\text { Harvesting }\end{array}$ & $\begin{array}{c}\text { Örnek sayısı } \\
\text { Samples Number }\end{array}$ & $\begin{array}{c}\text { Minimum } \\
\text { Minimum }\end{array}$ & $\begin{array}{c}\text { Maksimum } \\
\text { Maximum }\end{array}$ & $\begin{array}{c}\text { Ortalama } \\
\text { Average }\end{array}$ & $\begin{array}{c}\text { Standart sapma } \\
\text { Standard deviation }\end{array}$ \\
\hline 1. Biçim/Harvest & 87 & Yaprak Oranı/Leaf Ratio (\%) & & & \\
2. Biçim/Harvest & 67 & 49.01 & 93.00 & 66.47 & \pm 7.21 \\
\hline Ortalama/Average & & 44.00 & 94.00 & 76.25 & \pm 8.12 \\
\hline
\end{tabular}

Suda Çözünmüş Kuru Madde Oranı/Water Dissolved Dry Matter Ratio (\%)

\begin{tabular}{lccccc}
\hline \multicolumn{7}{c}{ Yaprak/Leaf } \\
\hline 1. Biçim/Harvest & 87 & 1.00 & 4.80 & 2.93 & \pm 0.49 \\
2. Biçim/Harvest & 67 & 0.90 & 3.50 & 1.86 & \pm 0.50 \\
\hline \multicolumn{1}{c}{ Ortalama/Average } & 0.95 & 4.15 & & \\
\hline & & Sap/Stem & & & \\
\hline 1. Biçim/Harvest & 87 & 0.90 & 3.20 & 2.26 & \pm 0.47 \\
2. Biçim/Harvest & 67 & 0.50 & 2.30 & 1.57 & \pm 0.61 \\
\hline \multicolumn{1}{c}{ Ortalama/Average } & 0.70 & 2.75 & & & \\
\hline
\end{tabular}

\section{Suda çözünmüş kuru madde oranı}

Çizelge 5.'te suda çözünmüş kuru madde oranlarının yaprakta 1. Biçimde, \%1.00-4.80 arasında değiştiği ve ortalama $\% 2.93 \pm 0.49$ olduğu, sapta \%0.90-3.20 arasında değiştiği ve ortalama $\% 2.26 \pm 0.47$ olduğu, 2. Biçimde yaprakta \%0.903.50 arasında değiştiği ve ortalama $\% 1.86 \pm 0.50$ olduğu, sapta ise \%0.50-2.30 arasında değiştiği ve ortalama $\% 1.57 \pm 0.61$ olduğu görülmektedir. Şeker otu suda çözünmüş kuru madde oranı, biçimlere ve organlara göre, büyük farklılık göstermiştir. Yapraklarda, sapa göre daha fazla suda çözünmüş kuru madde oranı gözlenmiştir. Ayrıca, her iki bitki akasamında da, 1. biçimde, suda çözünmüş kuru madde oranı daha yüksek saptanmıştır. Bulgularımız, yapraktaki steviol oranın daha yüksek olduğunu bildiren Uçar (2015)'ın bulgularıla uyumludur.

\section{Korelasyon ( $r$ ) analiz sonuçları}

Denemede, 2016 yılı yaz döneminde, şeker otu bitkisinde, incelenen özellikler arası ilişkilere ilişkin korelasyon ( $r$ ) sonuçları Çizelge $6^{\prime} \mathrm{da}$ verilmiştir.

Çizelge 6. Denemede, 1. Biçimde incelenen tarımsal özellikler arası korelasyon analizi sonuçları

Table 6. The results of the correlation analysis between the agricultural characteristics examined in the first harvest

\begin{tabular}{|c|c|c|c|c|c|c|c|c|c|}
\hline & $\mathrm{BB}$ & SS & YS & YHV & YYV & KYV & $\mathrm{KHV}$ & YO & SSÇKM \\
\hline SS & $0.200^{*}$ & & & & & & & & \\
\hline YS & 0.163 & 0.034 & & & & & & & \\
\hline YHV & $0.353^{* *}$ & $0.291^{* *}$ & 0.126 & & & & & & \\
\hline YYV & $0.475^{* *}$ & $0.229^{*}$ & 0.138 & $0.748^{* *}$ & & & & & \\
\hline KYV & $0.461^{* *}$ & 0.159 & 0.054 & $0.646^{* *}$ & $0.829^{* *}$ & & & & \\
\hline KHV & $0.463^{* *}$ & 0.230 & 0.048 & $0.643^{* *}$ & $0.701^{* *}$ & $0.851^{* *}$ & & & \\
\hline YO & $0.214^{*}$ & 0.142 & 0.182 & $0.712^{* *}$ & $0.438^{* *}$ & $0.392^{* *}$ & $0.214^{*}$ & & \\
\hline SSÇKM & 0.161 & 0.109 & 0.012 & $0.272^{*}$ & 0.154 & 0.101 & $0.201^{*}$ & 0.093 & \\
\hline YSÇKM & 0.170 & 0.020 & -0.006 & $0.216^{*}$ & 0.123 & 0.098 & $0.201^{*}$ & 0.098 & 0.079 \\
\hline
\end{tabular}

BB: Bitki Boyu/plant height, SS: Sürgün Sayısı/sprout number, YS: Yandal Sayısı/branches number, YHV: Yeşil Herba Verimi/green herb yield, YYV: Yeşil Yaprak Verimi/green leaf yield, KYV; Kuru Yaprak Verimi/dry leaf yield, KHV; Kuru Herba Verimi/dry herb yield, YO; Yaprak Oranı/leaf ratio, SSÇKM; Sapta Suda Çözünmüş Kuru Madde/water dissolved dry matter ratio in stem, YSÇKM; Yaprakta Suda Çözünmüş Kuru Madde/water dissolved dry matter ratio in leaf 
Çizelge 6.'da görüldüğü gibi, alınan sonuçların 1>r>-1 aralığında olup, bitki boyu, ocakta sürgün sayısı, yandal sayısı, yeşil herba verimi, yeşil yaprak verimi, kuru yaprak verimi özellikleri arasında pozitif korelasyon, suda çözünmüş kuru madde bazı verilerinde negatif korelasyon olduğu ve değişkenler arasında doğrusal olmayan bir bağ olduğu görülmektedir.

Bitki boyu ile ocakta sürgün sayısı, yeşil herba verimi, yeşil yaprak verimi, kuru yaprak verimi, kuru herba verimi ve yaprak oranı arasında önemli-olumlu ancak, yandal sayısı, sapta ve yaprakta suda çözünmüş kuru madde oranı arasında ise olumlu ancak önemsiz ilişki saptanmıştır.

Ocaktaki sap sayısı ile yeşil herba, yeşil yaprak verimi arasında olumlu-önemli, yandal sayısı, kuru yaprak verimi, kuru herba verimi, yaprak oranı, sapta ve yaprakta suda çözünmüş kuru madde oranı arasında ise olumlu ancak önemsiz ilişki saptanmıştır.

Yandal sayısı ile yeşil herba verimi, yeşil yaprak verimi, kuru yaprak verimi, kuru herba verimi ve sapta suda çözünmüş kuru madde oranı arasında olumlu-önemsiz ve yaprakta suda çözünmüş kuru madde oranı arasında olumsuz-önemsiz ilişki saptanmıştır.

Yeşil herba verimi ile yeşil yaprak verimi, kuru yaprak verimi, kuru herba verimi, sapta ve yaprakta suda çözünmüş kuru madde oranı arasında olumlu-önemli ilişki olduğu belirlenmiştir.

Yeşil yaprak verimi ile kuru yaprak verimi, kuru herba verimi ve yaprak oranı arasında olumluönemli, sapta ve yaprakta suda çözünmüş kuru madde oranı arasında ise olumlu ancak önemsiz ilişki saptanmıştır.

Kuru yaprak verimi ile kuru herba verimi ve yaprak oranı arasında olumlu-önemli, sapta ve yaprakta suda çözünmüş kuru madde oranı arasında ise olumlu ancak önemsiz ilişki saptanmıştır.

Kuru herba verimi ile bitki boyu, yeşil herba verimi, yeşil yaprak verimi, kuru yaprak verimi, yaprak oranı, sapta ve yaprakta suda çözünmüş kuru madde oranı arasında olumlu-önemli ilişki saptanmıştır.

Yaprak oranı ile bitki boyu, yeşil herba, yeşil yaprak verimi, kuru herba ve kuru yaprak verimi arasında olumlu-önemli derecede ilişkili, yandal sayısı ve ocakta sürgün sayısı arasında olumlu ancak önemsiz derecede ilişki belirlenmiştir.

Suda çözünmüş kuru madde oranları yaprak ve saptaki oranlar korelasyon katsayıları arasındaki ilişki incelendiğinde; yeşil herba verimi ile kuru herba veriminin olumlu ve önemli derecede etkisinin olduğu görülmektedir.

Korelasyon katsayıları arasındaki ilişkiler yeşil herba, yeşil yaprak ağırlığının ve yaprakta suda çözünen kuru madde oranının önemini vurgulamakla beraber, çalışmanın yürütüldüğü iklim koşullarının büyük etkisi olduğunu, yeşil herba, yeşil dal ağırlığının ve dalda suda çözünmüş kuru madde oranının korelasyon katsayılarının önemli ve olumlu olması, tropikal iklimin dal gelişimine ağırlık vermesinden kaynaklandığını bildiren sonuçları destekler niteliktedir (Francisco ve ark., 2018).

\section{Sonuç ve Öneriler}

Günümüzde, diyabet dünyanın en yaygın hastalıklarından birisidir ve diyabet hastalarının kullanabileceği tatlandırıcılar konusundaki çalışmalara büyük önem verilmektedir. Bu konuda üzerinde en fazla durulan bitkilerden birisi de şeker otu bitkisidir. Şeker otu, Ülkemizde yetiştiriciliği henüz yaygınlaşmamış ve yeterince bilimsel çalışma yapılmamış bir bitki olup, bölgede yapılacak çalışmalara ve bilgi birikimine katkı sağlamak amacıyla yürütülen bu çalışmada, elde edilen sonuçlar değerlendirildiğinde, Harran Ovası koşullarında, şeker otunun yüksek sıcaklıklardan özellikle 2. Biçimlerde olumsuz yönde etkilendiği, 1. Biçimde Fusarium sp.'nin neden olduğu solgunluk hastalığının görülebileceği belirlenmiştir. Korelasyon analizi sonuçlarına göre ise, kuru herba verimi üzerine, bitki boyu, yeşil herba verimi, yeşil yaprak verimi, kuru yaprak verimi, yaprak oranı, yaprak ve sapta suda çözünmiş kuru madde oranlarının olumlu ve önemli derecede katkısı olduğu saptanmıştır. 
Çalışmadan elde edilen sonuçlar genel olarak değerlendirildiğinde, Harran Ovası koşullarında, şeker otu bitkisinin yetişebileceği, uygun genotip ve yetiştirme tekniği ile yılda en az iki biçim alınabileceği söylenebilir. Ancak, 1. Biçimde serin ve yağışlı geçen dönemlerde şeker otu bitkisinde bazı toprak kökenli hastalıkların görülebileceği ve 2. Biçimde aşırı sıcaklıklardan olumsuz yönde etkilenebileceği söylenebilir. Bu nedenlerle bölge koşullarında yüksek verim ve kaliteli üretim için, olası hastalıklara dayanıklı genotiplerin belirlenmesi ve yetiştirme tekniği çalışmalarının yapılması gereklidir.

\section{Ekler}

Bu çalışma, HÜBAK Tarafından Desteklenen (Proje No: 17033), Yüksek Lisans Tezinden hazırlanmıştır.

\section{Kaynaklar}

Aladakatti, Y.R. (2011). Response of stevia (Stevia rebaudiana Bertoni.) to irrigationschedule, planting geometry and nutrient levels. Department of Agronomy College of Agriculture. Ph.D. Thesis, Dharwad University of Agricultural Sciences

Allam A.I., Nassar, A. \& Besheti, S.Y. (2001). Nitrogen fertilizer requirements of Stevia rebaudiana under Egyptian conditions. Egyptian Journal of Agricultural Research, 79(3): 1005-1018.

Andolfi, L., Macchia, M., \& Ceccarini, L. (2006). Agronomic Productive Characteristics of Two Genotype of Stevia Rebaudiana in Central Italy. Ital. J. Agrn. 2: 257-262.

Angeliana, L.G. \& Tavaranini S. (2014). Crop Productivity, Steviol Glycoside Yield, Nutrient Concentration and Uptake of Stevia rebaudiana Bert. under Mediterranean Field Conditions, Department of Agriculture, Food and Environment, The University of Pisa, Italy

Anonim

https://www.tarimorman.gov.tr/konu/957/bitki-

listesi. Erişim Tarihi: 01.04.2019

Atalay, i. \& Mortan, K. (2006). Türkiye Bölgesel Coğrafyası, İnkılap Yayınları, İstanbul.

Baydar, H. (2013). Tıbbi ve Aromatik Bitkiler Bilimi ve Teknolojisi. Süleyman Demirel Üniversitesi Ziraat Fakültesi Yayınları, Yayın No:51, Isparta

Bayram, E., Kırıcı, S, Tansı S, Yılmaz, G, Arabacı, O., Kızıl, S. \& Telci, D. (2010). Tıbbi ve Aromatik Bitkiler Üretiminin Arttırılması Olanakları. Türkiye Ziraat Mühendisliği VII.Teknik Kongresi Bildiriler Kitabı, 11-15 Ocak, ANKARA, 437-456.

Bondarev, N.I., Sukhanova, O.V., \& Nosov, A.M. (2003). Steviol Glycoside Content in Different Organs of Stevia rebaudiana and It's Dynamics During
Ontogeny. Biologia Plantarun, 47(2): 261-264.

Carakostas, M.C., Curry, L.L., Boileau, A.C. \& Brusick, D.J. (2008). Overview: the history, technical function and safety of rebaudioside $A$, a naturally occurring steviol glycoside, for use in food and beverages, Toxicol., 46(7S):1-10.

Ceylan, A. (1994). Tarla Tarımı. Ege Üniversitesi Ziraat Fakültesi Yayınları, No: 491, $107 \mathrm{~s}$.

Dinç. U., Şenol. S., Sayın. M., Thompson. D.S., Sobeih W. \& Rodriguez. G. (1988). Güneydoğu Anadolu Topraklar (GAT) 1. Harran Ovası. Tübitak Tarım ve Ormancılık Araştırma Projesi. No: TOAG -433. Adana.

Francisco, F., Pereira, G.P., Machado, M., Kanis, L.A. \& Deschamps, C. (2018). Characterization of Stevia rebaudiana Bertoni Accessions Cultived in Southern Brazil, Journal of Agricultural Science; Vol. 10, No. 3; 2018.

İnanç, L. \& Çınar, ì. (2009). Alternatif doğal tatlandırıcı: Stevya. Gıda Dergisi 34(6): 411-415.

Kang, K., \& Lee, E.W. (1981). Physio-ecological studies on Stevia (Stevia rebaudiana Bertoni). Korean J. Crops Sci., 26: 69-89.

Kumar, R., Sharma, S., Ramesh, K., \& Singh, B. (2012). Effects of Shade Regimes and Planting Geometry on Growth, Yield and Quality of Natural Sweetener Plant Stevia (Stevia rebaudiana Bertoni) in North Western Himalaya. Agronomy and Soil Science, 59 (7): 963979.

Lee, J.I., Kang, K.H., Park, H.W., Ham, Y.S. \& Park, C.H. (1980). Studies on the new sweetening source plant, Stevia rebaudiana in Korea II. Effects of fertilizer rates and planting densities on dry leaf yields and various agronomic characteristics of Stevia rebaudiana. Research Reports of the Office of Rural Development, Suwan, 22: 138-144.

Lubbe, A. \& Verpoorte, R. (2011). Cultivation of Medicinal and Aromatic Plants for Specialty Industrial Materials. Industrial Crops and Products, 34: 785801.

Maniruzzaman, M.D., Chowdhury, A.H., Chowdhury, T. \& Hasan, A.B.M. (2016). Critical leaf concentration and requirement of stevia grown in two different soils of Bangladesh. Crop Science 1(3): 106-111 Fund Appl Agric 2016.

Maheshwar, H.M. (2005). Effect of Different Levels of Nitrogen and Gates of Planting on growth and Yield of Stevia (Stevia rebaudiana Bert.). Master thesis, Department of Horticulture College of Agriculture, Dharwad Univerity of Agricultural Sciences.

Megeji, N.W., Kumar, J.K., Sıngh, V., Kaul, V.K. \& Ahuja, P.S. (2005). Introducing Stevia rebaudiana a Natural Zero-Calorie Sweetener. Curr. Sci., 88(5): 31-35.

Ramesh, K., Sıngh, V. \& Megejı, N. (2006). Cultivation of Stevia (Stevia rebaudiana (Bert) Bertoni): A comprehensive review. Advances in Agronomy, 89: 137- 177.

Rashid, Z., Rashid, M., Inamullah, S., Rasool, S. \& Bahar, F. (2013). Effect of Different Levels of Farmyard Manure and Nitrogen on the Yield and Nitrogen Uptake by Stevia (Stevia rebaudiana Bertoni). African Journal of Agricultural Research, 8(29): 3941-3945.

Serfaty, M., Ibdah, M., Fisher, R., Saranga, Y. \& Nativ, D. (2013). Dynamics of yield components and stevioside 
production in Stevia rebaudiana grown under different planting times, plant stands and harvest regime. Industrial Crops and Products, 50:731-73.

Shyu, Y.T., Lu, H.Y., Wu, W.K. \& Su, C.G. (1994). Effects of harvesting dates on the characteristics, yield, and sweet components of stevia lines. Journal of Agriultural Research China, 43: 29-39.

Singh, S. D. \& Rao, G. P. (2005). Stevia: The herbal sugar of the $21^{\text {st }}$ century. Sugar Technol. 7:17-24.

Tansı, S.L., Samadpourrigan, E., Gedik, S. \& Soltanbeigi, A. (2017). Ontogenetik varyabilite ve bitki yoğunluğunun şeker otu verimine etkisi. KSÜ Doğa Bil. Derg., 20: 323-326.
Uçar S.E. (2015). Şeker otu (Stevia rebaudiana Bertoni) Bitkisinin Bazı Verim ve Kalite Özellikleri Üzerine Farkli Azot Dozlarının Etkisi. Akdeniz Üniversitesi Ziraat Fakültesi, Fen Filimleri Ensitüsü, Doktora Tezi S:111, Antalya.

Yadav, A. K., Singh, S., Dhyani, D. \& Ahuja, P. S. (2011). A review on the improvement of stevia [Stevia rebaudiana (Bertoni)]. Can. J. Plant Sci., 91:1-27.

Zaidan, L.B., Dietrich, S.M. \& Felippe, G.M. (1980). Effect of Photoperiod on Flowering and Stevioside Content in Plants of Stevia rebaudiana Bert. Journal Crop Sci., 49(4): 569-574. 